\title{
Odours and the Sense of Smell.
}

\section{By Dr. J. H. KenNeth.}

GROM year to year the number and extent of specialised investigations of the organs and sense of smell and of odorous substances is steadily increasing. There are few treatises which deal with the subject in a comprehensive manner, and none which could be termed exhaustive. The reasons for this deficiency in scientific literature are many, the main reason being the difficulty of combining, except by means of a symposium, expert knowledge of each of the many different subjects which coalesce in the science of smell. Boyle's "Exercitationes" (I672), Cloquet's "Osphrésiologie" (I82I), Zwaardemaker's "Physiologie des Geruchs" (1895), and "L'Odorat" (1925), the presidential address to Section A of the British Association (1898), by Prof. Ayrton; Haycraft on "The Sense of Smell" (I900), Henning's "Der Geruch" (I9I6), the "Essai d'olfactique physiologique," by Heyninx (rgr9), and "Smell, Taste, and Allied Senses in the Vertebrates," by G. H. Parker (I922), are some of the outstanding efforts towards an integration of the heterogeneous elements composing the science of smell. This co-ordination of special knowledge comprised in the science of smell (olfactology, osphrésiologie, Geruchslehre) in its widest interpretation may conveniently be termed 'osmics' (l'osmique, osmica, Osmik).

The subject may be divided into three main and interdependent aspects or foci; morphological, psychophysiological, and physico-chemical. In addition there would be included all the numerous applications engendered by the science in its different aspects.

The morphological division, again, may be divided into two parts-one dealing with the structure and development of the peripheral and central olfactory apparatus (osphrenes), and the other with the structure of odorous apparatus (osmenes), both in health and disease. There are many anatomical, histological, and embryological data available; for example, accounts of the olfactory mucous membrane of the frog, the olfactory nerve of the goose, the absence of olfactory pigment in albinos, hippocampal abnormalities in epileptics, scent organs of butterflies, and the odorous gland of the chamois, to mention some at random. All these many isolated observations require some sorting out and co-ordination, not merely in order to facilitate knowledge of morphological work already done, but also to stimulate and direct further research and integration of knowledge. Even the comparative histology of the olfactory mucous membrane, or that of the vomero-nasal organ, has yet to be completed, let alone the comparative morphology of osphrenes and osmenes as a whole. Consideration is also due to the connexions between the olfactory apparatus and other parts of the body, such as endocrines and the sexual apparatus. Osmics thus provides a most extensive field of research, not only for the individual morphologist, but for team work.

While noses have an interest all of their own, it is their performances which make a wider and more intensive appeal. From the mysteries of good and evil as represented by fragrances and stinks, to the examina- tion of the psycho-galvanic response to the action of hydrogen sulphide and amyl acetate on the lipoids in the hairs of the olfactory cells, is a far cry, a cry dimly perceived by the osmic as well as by the cosmic philosopher. The general study of reactions to olfactory stimuli is not easily systematised, partly owing to the prolonged courtship between physiology and psychology. However, a discussion of some of the problems requiring elaboration will indicate the scope of the physiological and psychological aspects.

To begin with, the nature of olfactory stimulation is not yet satisfactorily understood. The general opinion would favour the theory that it is induced by some form of solution of the odorous molecule (odorivector, Geruchsträger). The minimum number of such odoriferous molecules necessary to produce an olfactory sensation is estimated by Prof. Zwaardemaker to be $20 \times 10^{8}$ in one nasal fossa. The intensity of the sensation would appear to depend on the number of molecules impinging on the olfactory mucous membrane, while the quality of the sensation depends on the molecular structure of the odorivector. According to Heyninx, the quality of the olfactory sensation depends on the wave-length of the molecular vibration, only such wave-lengths being sensed as lie between $0.35 \mu$ and $0.20 \mu$. He does not record the inference that this theory would account for the greater liminal range in many animals. Further, following conclusions by Parks which have been quoted by Chwolson, the molecules would form a layer of $0.13 \mu$ in thickness on the surface of the olfactory membrane. Their vibration would be transmitted to the olfactory hairs and cells. Heyninx suggests that the olfactory pigment functions so as to provide something like resonance. It has occurred to the writer that such 'resonance' may be due to one of the primary functions of the pigment being possibly that of a protective screen against overstimulation of structures in the corium of the olfactory mucous membrane, by ultra-violet activity.

A considerable amount of work has been done by various observers, chiefly by Zwaardemaker, on the measurement of olfactory acuity (olfactometry) in health and disease. Observations on the senses of the Todas, by Rivers, and experiments on Javanese and Europeans, by Grijns, adumbrate a more extensive investigation of olfactory acuity in the different races of mankind. More quantitative data than are now available on the olfactory acuity of animals are also desirable. Of interest here, too, is the measurement of simple reaction time, which has been carried out by Buccola, Moldenhauer, Vaschide, and requires amplification and comparison with association time. Crude stop-watch experiments tend to show that in a given individual the time required for smell-word association does not seem to differ from that for wordword association; but there is a difference which requires demonstration by more exact methods of experimentation.

Another interesting field for research is the investigation of olfactory reflexes and odour preferences. There are inborn and acquired likes and dislikes, which form 
a kind of olfactory syndrome or diathesis characteristic of the individual. Owing to fluctuations in the affective judgment of odours due to changes in metabolic conditions, it would seem probable that an olfactory diathesis would have some diagnostic value, especially if linked with an examination of colour preferences.

Although the history of perfumery gives much information with regard to odour preferences among different peoples, experiments on a large scale are desirable in order to correlate affective judgments with other factors, such as pigmentation, endocrine balance, etc. Quite an appreciable amount of work has been done on the question of smell and sex, but there is room for further investigation. The problem of preferences is intimately related to the examination of olfactory associations. When dealing with familiar odours, the percentage of failures to form ascertainable associations is relatively small, according to recent (I924) experiments only about $5_{5}$ per cent. The fact that olfactory associations are very largely formed unawares, makes their investigation of some practical importance, especially when linked up with olfactory associations occasionally occurring in dreams. An odour constitutes a more effective characterisation of persons, objects, and places than a verbal description, and the absence of a direct vocabulary of olfactory sensations raises difficulties. However, the images called up by odours are so vivid that there would seem to be a case for their occasional employment in the practice of psycho-analysis. Another suggestion is to employ odours to induce certain 'moods' for therapeutic purposes, and perhaps, in time, the ancient use of burned feathers may develop into a system of osmotherapy based on a wide knowledge of olfactory reactions.

Olfactory fatigue has not been mentioned, nor the problem of a classification of odours, nor methods of educating the sense of smell, nor a tithe of the many problems awaiting co-ordination and further research by the physiologist and psychologist. The plethora of osmics is further indicated by the multitude of problems arising from a consideration of the nature of odorous substances (osmyls).

The relations between odour and chemical constitution, emphasised by Haycraft, Cohn, Durrans, and others, by the increasing number of investigations carried out in the industry of perfumery and flavouring materials, has been further extended by recent research on phenomena connected with odorous particles. Tyndall's discovery of the absorption of radiant heat has led to the examination of infra-red absorption by Grijns and the ultra-violet absorption bands by Heyninx, and of correlated phenomena. It is not yet possible to draw satisfactory phvsiological conclusions from these investigations (the interpretations of which are open to criticism), but it can be stated that potential molecular energy may act on the olfactory cells. Zwaardemaker and Hogewind (r920) have pointed out that in homologous series there is an increase in diamagnetism exactly proportional to the number of atoms in the molecule. However, even Zwaardemaker (r925) is obliged to acknowledge that the precise nature of the olfactory stimulus has not yet been satisfactorily explained, but that "il y a de nombreuses perspectives pleines de promesses, qui pourront être dévoilées en continuant la recherche physique." Even this most cursory and incomplete account of some of the innumerable problems tends to show the need for coordination and direction of research, not merely in the interests of pure science, but also on account of the numerous applications in everyday life, in industry, and in medicine. There is ample justification for the organisation of the science of smell as a whole, in order that existing data may be integrated and further research may be organised and directed.

\section{The Geological Age of the Earth. ${ }^{1}$}

$\mathrm{C}_{\mathrm{N}}$ delivering the twenty-seventh Robert Boyle lecture last year, Prof. J. Joly returned to his attack on the higher estimates of geological time which have been based on the lead-ratios of uranium-bearing minerals. He favours an estimate of $x 60$ to 240 millions of years for the period that has elapsed since the Archæan, and refers to the lead-ratios of certain thorium minerals and to the sodium method of arriving at the age of the oceans as providing confirmatory evidence. It can, I think, be shown that in both cases the data used are misleading, and that the results from both methods can be readily interpreted to support the very estimates to which Prof. Joly considers they are opposed.

On the assumption of uniformitarianism, the salinity of the ocean points to an age of about 80 to roo million years. The amount of sodium in the oceans has been determined with sufficient accuracy to justify the method, but this cannot be said of the annual increment of sodium brought down to the sea by the rivers. Denudational statistics show that for all the open drainage areas of the world, the total amount of sodium removed in solution is more than $2 \cdot x$ per cent of the material mechanically and chemically removed from the lands. On the other hand, the rocks actually ex-

1 Oxford University Press, I926, pp. 18. Is. posed to denudation contain on an average only $\mathrm{I} \cdot 3$ per cent. of sodium. Thus it appears that the rocks would have to lose more sodium than they had ever contained in order to supply the amounts alleged to have been added annually to the oceans.

Four partial and independent explanations of this remarkable discrepancy can be suggested. (a) To a slight extent the discrepancy is mitigated by the fact that part of the material liberated by denudation remains on the lands and is largely left out of account in the above calculations. (b) Many of the analyses of river-waters for sodium have probably been inaccurate; for unless extraordinary precautions had been taken to overcome the difficulties inherent in such analyses the results would usually be too high. (c) It is also probable that part of the sodium carried by the rivers is cyclic, and the invariable presence of chlorine in riverwaters supports this contention. The amount of chlorine in igneous and other rocks is hopelessly inadequate to provide the quantities found in rivers. Volcanic and other juvenile sources have doubtless served to supply most of the chlorine now accumulated in the oceans, but analyses of rain-water show that volcanic sources cannot be of appreciable importance at the present day. The high relief of the existing 